EXTENDED REPORT

\title{
Thrombophilic factors are not the leading cause of thrombosis in Behçet's disease
}

\author{
M Leiba, U Seligsohn, Y Sidi, D Harats, B A Sela, J H Griffin, A Livneh, N Rosenberg, I Gelernter, \\ H Gur, M Ehrenfeld
}

Ann Rheum Dis 2004;63:1445-1449. doi: 10.1136/ard.2003.014241

See end of article for authors' affiliations

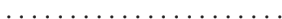

Correspondence to:

Dr M Ehrenfeld

Department of Medicine C,

Sheba Medical Centre, Tel-

Hashomer 52621, Israel;

ehrenfel@post.tau.ac.il

Accepted

10 December 2003
Background: Venous and arterial thromboses occur in patients with Behçet's disease and are associated with significant morbidity and mortality. Studies on a possible association between the occurrence of thrombosis and thrombophilia in patients with this disease have been controversial.

Objective: To determine the prevalence of the most common thrombophilias and dyslipidaemia in patients with Behçet's disease with and without thrombosis.

Methods: Blood samples from 107 patients with Behçet's disease who had or did not have thrombosis were analysed for factor $V$ Leiden, prothrombin G20210A polymorphism, methylenetetrahydrofolate reductase (MTHFR) C677T polymorphism, factor VIII level, homocysteine and C reactive protein concentrations, dyslipidaemia, and plasma glucosylceramide.

Results: There was no difference between patients with and without thrombosis in the prevalence of prothrombin G20210A polymorphism, factor V Leiden, homozygous MTHFR C677T, or plasma concentrations of homocysteine, C reactive protein, or glucosylceramide. In contrast, patients with thrombosis were found to have significantly higher mean levels of factor VIII, total cholesterol, triglycerides, VLDL cholesterol, and apolipoproteins B-100, C-II, and C-III than those without thrombosis. Multistepwise logistic regression analysis showed that triglyceride concentration was the best marker associated with thrombosis $(p=0.008)$, with an estimated odds ratio of 1.58 (95\% confidence interval, 1.09 to 2.30$)$ for a difference of $40 \mathrm{mg} / \mathrm{dl}$.

Conclusions: Thrombophilia does not seem to play a major role in the tendency to thrombosis in Behçet's disease. However, dyslipidaemia, predominantly hypertriglyceridaemia, might be a risk factor.
B ehçet's disease is a chronic multisystem inflammatory disorder that can involve the skin, eyes, central nervous system, arteries, veins, lungs, and gastrointestinal tract. The common manifestations are recurrent oral and genital ulcers and ocular inflammation. Venous or arterial thromboses occur in $7-38 \%$ of patients. ${ }^{1}$ Venous thrombosis is more common than arterial thrombosis, with relative frequencies of $90 \%$ and $10 \%$, respectively. Deep or superficial venous thromboses in the lower extremities are the common sites of thrombosis. $^{23}$

Vasculitis underlies the thrombotic tendency in Behçet's disease, but it is not clear why some patients present with thrombosis and others do not. Decreased levels of tissue plasminogen activator and thrombomodulin, and increased levels of plasminogen activator inhibitor-1, von Willebrand factor, thrombin-antithrombin complex, prothrombin fragment $1+2$, and lipoprotein (a) $(\operatorname{Lp}(\mathrm{a}))$ have all been described in patients with Behçet's disease and related to the thrombotic tendency. ${ }^{4-6}$ The possible role of acquired and inherited thrombophilias has also been evaluated. However, there are conflicting data in patients with and without thrombosis over the prevalence of factor $\mathrm{V}$ Leiden, methylenetetrahydrofolate reductase (MTHFR) C677T homozygosity, homocysteine level, prothrombin G20210A polymorphism, and levels of factor VIIa, factor VIII, and factor XII. ${ }^{4} \mathrm{~A}$ recently described thrombophilic index-decreased plasma glucosylceramide concentration-has not been examined yet in patients with Behçet's disease. ${ }^{7}$

Our aim in this study was to determine, in a relatively large cohort of patients with Behçet's disease with and without thrombosis, the prevalence of common thrombophilic factors such as factor V Leiden, prothrombin G20210A, homozygous
MTHFR C677T, and increased levels of factor VIII and homocysteine. We also measured $\mathrm{C}$ reactive protein, plasma glucosylceramide, and indices of dyslipidaemia.

\section{METHODS}

\section{Study group}

Records of patients with Behçet's disease who attended the Sheba Medical Centre between 1984 and 1999 were reviewed. The initial cohort with a diagnosis of Behçet's disease according to the computerised survey included 175 patients, 10 of whom had died over the years and were thus not included in the study. Of the remaining 165 patients, 58 were either non-cooperative, did not fit the inclusion criteria, or were lost to follow up.

All living patients were invited for an interview and a detailed history was taken. The institutional review board of the Sheba Medical Centre approved the study, and informed consent was obtained from all participants. The diagnostic criteria of the International Study Group for Behçet's disease were used for inclusion. ${ }^{8}$ Age, sex, body mass index (BMI), disease duration, symptoms, drugs, and past thrombotic events were recorded. Based on the history and the medical records, patients were categorised into those with a history of venous or arterial thrombosis and those without such events. Venous thromboembolic events were regarded as such when imaging examinations-that is, Doppler and compression ultrasonography, angiography, or ventilation-perfusion lung scans-were consistent with the diagnoses of deep vein

Abbreviations: DVT, deep vein thrombosis; $L p(a)$, lipoprotein (a); MTHFR, methylenetetrahydrofolate reductase; SVT, superficial vein thrombosis 
Table 1 Differences in clinical manifestations in patients with Behçet's disease with and without thrombosis

\begin{tabular}{|c|c|c|c|}
\hline Manifestations & $\begin{array}{l}\text { Patients with thrombosis } \\
(\mathrm{n}=33), \% \text { affected }\end{array}$ & $\begin{array}{l}\text { Patients without } \\
\text { thrombosis }(n=74), \% \\
\text { affected }\end{array}$ & $\begin{array}{l}p \text { Value for } \\
\text { difference }\end{array}$ \\
\hline Skin lesions & 72 & 63 & 0.25 \\
\hline Recurrent genital ulcers & 72.7 & 48.6 & 0.022 \\
\hline Eye lesions & 72.7 & 44.5 & 0.034 \\
\hline Arthritis and arthralgia & 78.7 & 78.3 & 0.95 \\
\hline Gastrointestinal involvement ${ }^{\star}$ & 39.4 & 15 & 0.011 \\
\hline Central nervous system $†$ & 48.5 & 16.7 & 0.002 \\
\hline Positive HLA B5 $\ddagger$ & 33.3 & 26.3 & 0.56 \\
\hline Smoking & 39.4 & 25.7 & 0.17 \\
\hline
\end{tabular}

*Abdominal pain, diarrhoea, constipation.

†Manifestations not related to thrombosis: headache, numbness, paraesthesiae, pseudotumor cerebri, paresis

without imaging evidence of thrombosis.

‡Only 21 patients with thrombosis and 38 patients without thrombosis were examined.

HLA, human leucocyte antigen.

thrombosis or pulmonary embolism, respectively. Cerebral artery thrombosis was diagnosed by computed tomography or magnetic resonance imaging, and transient ischaemic attacks by a typical clinical presentation. Myocardial infarction was diagnosed by typical clinical presentation, ECG changes, and raised levels of troponin or other cardiac enzymes.

After 12 hours of fasting, venous blood was drawn from all patients. From those who had thrombosis, blood was taken at least three months after the event. Blood was collected in EDTA for DNA extraction and measurements of homocysteine and $C$ reactive protein, and in buffered citrate for assays of factor VIII and plasma glucosylceramide. Plasma was separated soon after taking blood. Serum was separated from clotted blood for analysis of the lipid profile.

\section{Analysis of prothrombotic polymorphisms}

DNA extraction was carried out by a standard method. Factor $\mathrm{V}$ Leiden (G1691A) was detected by polymerase chain reaction (PCR) and MnlI digestion, MTHFR C677T by PCR and HinfI digestion, and prothrombin G20210A as previously described. ${ }^{9}$

Factor VIII level was measured by an aPTT based assay using factor VIII immunodepleted plasma. Commercial human freeze dried reference plasma was used to construct a standard curve. The normal range of factor VIII level was 60 to $160 \mathrm{U} / \mathrm{dl}( \pm 2 \mathrm{SD})$.

\section{Homocysteine concentration}

Homocysteine concentration was measured following labelling of plasma with monobromobimane for fluorescence detection after separation by high performance liquid chromatography (HPLC). ${ }^{10}$ This method measures total homocysteine (free and protein bound) and mixed disulphides. The normal values in adults ranged between 5 and $15 \mu \mathrm{mol} / \mathrm{l}( \pm 2 \mathrm{SD})$.

\section{$C$ reactive protein}

$\mathrm{C}$ reactive protein level was measured by a highly sensitive turbidimetric method using Olympus AU 2700 apparatus. The upper limit of the normal range (+2 SD) was $5 \mathrm{mg} / \mathrm{l}$.

\section{Lipid profile}

Serum total cholesterol, high density lipoprotein (HDL) cholesterol, low density lipoprotein (LDL) cholesterol, very low density lipoprotein (VLDL) cholesterol, and triglycerides were determined by colorimetric enzymatic procedures with an Olympus autoanalyser which was standardised against reference samples kindly provided by the standardisation programme of the Centers for Disease Control, USA. The
Olympus system for direct determination was used for HDL measurement. Serum concentrations of apoliproteins A-I, B-100, C-II, C-III, and Lp(a) were measured by an immunoturbidometric technique. Apo C-II was measured using Kamia Biomedical Company kit. The within-run and between-run assay coefficients of variation were $6 \%$ and $7 \%$, respectively. These results were similar to those obtained in other studies. ${ }^{11} 12$

\section{Glucosylceramide}

Glucosylceramide concentration in plasma was determined as described elsewhere, using HPLC analysis of organic solvent lipid extracts. ${ }^{7}$ The normal range ( $\pm 2 \mathrm{SD}$ ) was 4.85 to $9.59 \mu \mathrm{g} / \mathrm{ml}$.

\section{Statistical analyses}

Univariate analyses were carried out to compare subjects with and without thrombosis. Continuous variables were compared using $t$ tests. Discrete variables were compared using $\chi^{2}$ tests. Multivariate stepwise logistic regression was used to estimate the odds ratio for occurrence of thrombosis associated with potential risk factors among subjects with Behçet's disease. Age was included as a covariate in the logistic regression models to adjust for any age differences among subjects with and without thrombosis. One analysis considered only readily available clinical measurements as potential risk factors. A separate analysis also included specific measurements of apolipoproteins.

\section{RESULTS}

One hundred and seven patients (65 female and 42 male) met the inclusion criteria of Behçet's disease. Their mean age was 42.5 years at the time of diagnosis (range 12 to 78 ). The clinical manifestations of the patients are summarised in table 1. Seventy eight per cent of the patients were of Sephardic-Jewish origin, 13\% were Ashkenazi (European) Jews, and 9\% were of mixed origin. A mean delay of 10 years was noted from onset of manifestations until the diagnosis was made. Symptoms and signs did not differ between patients of different sex or ethnic origin, or between HLA-B5 positive and negative patients.

Thirty three patients (30.8\%) had a history of at least one thrombotic event. Eighteen (16.8\%) had venous thromboembolism, of whom 10 had deep vein thrombosis (DVT), four had superficial vein thrombosis (SVT) of a lower extremity, three had pulmonary embolism (in one this was associated with DVT), and one had hepatic vein thrombosis. Eleven patients $(10 \%)$ had arterial occlusions which involved the cerebral arteries in two, the coronary arteries in one, a peripheral artery of a lower extremity in two, and the central 
Table 2 Levels and prevalence of common thrombophilic factors and C reactive protein in Behçet's disease patients with and without thrombosis

\begin{tabular}{llll}
\hline Variable & $\begin{array}{l}\text { Patients with } \\
\text { thrombosis }(\mathbf{n = 3 3 )}\end{array}$ & $\begin{array}{l}\text { Patients without } \\
\text { thrombosis }(\mathbf{n = 7 4 )}\end{array}$ & $\begin{array}{l}\text { p Value for } \\
\text { difference }\end{array}$ \\
\hline Heterozygous factor V Leiden (\%) & 6.1 & 2.8 & 0.58 \\
Heterozygous prothrombin G20210A (\%) & 9.1 & 6.9 & 0.7 \\
Homozygous MTHFR C677T (\%) & 12.1 & 11.1 & 0.4 \\
Homocysteine $(\mu \mathrm{mol} / \mathrm{l})$ & $12.6(3.9)$ & $12.2(11.7)$ & 0.8 \\
C reactive protein $(\mathrm{mg} / \mathrm{l})$ & $5.6(6.9)$ & $5.65(9.8)$ & 0.8 \\
Glucosylceramide $(\mu \mathrm{g} / \mathrm{ml})^{*}$ & $6.8(0.4)$ & $6.5(0.2)$ & 0.62 \\
\hline
\end{tabular}

Values are per cent or mean (SD)

*Only 30 patients with thrombosis and 69 patients without thrombosis were tested.

MTHFR, methylenetetrahydrofolate reductase.

retinal artery in two. In addition, three patients had typical transient ischaemic attacks, and one had an aortic aneurysm. Four patients (3.7\%) had both arterial and venous thrombosis.

The mean time lag between diagnosis of Behçet's disease and blood sampling of the non-thrombotic group was 14.9 years (range 0 to 55 ), with a median of 13 years. The mean time lag between the thrombotic event and blood sampling was $7.0(4.3)$ years, with a median of 6 years (range 6 months to 15 years).

The mean (SD) age of patients with thrombosis was 45.6 (12.5) years and of patients without thrombosis, 41.0 (14.9) years. The occurrence of thrombosis was not significantly related to age, sex, ethnic origin, BMI, HLA-B5 status, or other diseases such as diabetes mellitus and hypertension. Furthermore thrombosis was not associated with any of the drugs used in Behçet's disease, including corticosteroids, colchicine, methotrexate, azathioprine, and cyclosporin A $(p=0.3-1)$. Patients who had a thrombotic event had a significantly higher frequency of recurrent genital ulcers and ophthalmic, gastrointestinal, and central nervous system manifestations (table 1).

Table 2 shows that there were no statistically significant differences between patients with and without thrombosis in the prevalence of the three common prothrombotic polymorphisms and concentrations of homocysteine, $\mathrm{C}$ reactive protein, and glucosylceramide. Similar non-significant differences were found when patients with arterial thrombosis alone were compared with those without thrombosis, as well as when the patients with venous thrombosis alone were compared with those without thrombosis. The only difference found was in the mean factor VIII level which was significantly higher in patients with thrombosis.
Mean concentrations of total cholesterol, triglycerides, VLDL, apolipoproteins A-I, B-100, C-II, and C-III were significantly higher in patients with thrombosis than in those without thrombosis (table 3). A separate analysis confined to patients with venous thrombosis showed that most concentrations of the measured lipid variables were still significantly higher than in patients without thrombosis.

Table 4 shows lipid profile variables and factor VIII activity according to their relative risk for thrombosis, comparing patients with Behçet's disease with and without thrombosis after adjustment for body mass index, age, and sex.

Among the standard clinical measurements, triglyceride concentration proved to be the best marker for the occurrence of thrombosis $(\mathrm{p}=0.008)$. Mean $(\mathrm{SD})$ triglyceride concentration in the patients without thrombosis was 1.16 (0.57) $\mathrm{mmol} / \mathrm{l}$ (the average value for triglycerides in our CDC controlled laboratory for an Israeli population matched for age and sex is $1.20(0.71) \mathrm{mmol} / \mathrm{l})$, and it was $1.73(1.04)$ $\mathrm{mmol} / \mathrm{l}$ in the patients with thrombosis. The estimated odds ratio for a difference of $0.45 \mathrm{mmol} / \mathrm{l}(40 \mathrm{mg} / \mathrm{dl})$ triglyceride was 1.58 (95\% confidence interval (CI), 1.09 to 2.30$)$. Although age and BMI were included in the logistic regression model, they had only a minor effect, reflecting the fact that patients with and without thrombosis had similar age and BMI distributions.

Once the effects of triglyceride and age were accounted for, no other variables made a statistically significant contribution to being a marker associated with the occurrence of thrombosis. The potential effect of factor VIII was examined more closely by fitting a logistic regression model with triglyceride, factor VIII, and age. The estimated odds ratio for a $20 \mathrm{U} / \mathrm{dl}$ increase in factor VIII was 1.39 (95\% CI, 1.002 to 1.92 ).

Table 3 Lipid concentrations, body mass index, and factor VIII activity levels in patients with Behçet's disease

\begin{tabular}{|c|c|c|c|c|}
\hline Variable & $\begin{array}{l}\text { Patients without } \\
\text { thrombosis }(n=74)\end{array}$ & $\begin{array}{l}\text { All patients with } \\
\text { thrombosis }(n=33 \text { ) }\end{array}$ & $\begin{array}{l}\text { Patients with arterial } \\
\text { thrombosis }(n=11) \S\end{array}$ & $\begin{array}{l}\text { Patients with venous } \\
\text { thrombosis }(n=18) \S\end{array}$ \\
\hline Total cholesterol (mmol/I) & $4.54(0.93)$ & $5.14(0.93) \ddagger$ & $5.39(0.83) \ddagger$ & $5.06(0.98) \dagger$ \\
\hline Triglyceride (mmol/l) & $1.16(0.57)$ & $1.73(1.04) \ddagger$ & $1.60(0.61) \ddagger$ & $1.82(1.20) \dagger$ \\
\hline LDL cholesterol (mmol/l) & $2.75(0.78)$ & $3.03(0.80)$ & $3.23(0.75) \ddagger$ & $2.98(0.80)^{*}$ \\
\hline HDL cholesterol (mmol/l) & $1.24(0.30)$ & $1.32(0.36)$ & $1.42(0.39)^{*}$ & $1.26(0.36)$ \\
\hline VLDL cholesterol (mmol/l) & $0.55(0.25)$ & $0.73(0.31) \ddagger$ & $0.74(0.28) \dagger$ & $0.73(0.32) \dagger$ \\
\hline $\mathrm{Lp}(\mathrm{a})(\mathrm{mg} / \mathrm{dl})$ & $21.2(16.0)$ & $20.9(14.0)$ & $25.5(16.0)$ & $16.5(13.0)$ \\
\hline Apo A-I (mg/dl) & $120.4(19.0)$ & $129.0(24.0)^{*}$ & $135.2(20.0) \ddagger$ & $125.8(26.0)^{*}$ \\
\hline Apo B-100 (mg/dl) & $82.9(24.0)$ & $97.9(21.0) \ddagger$ & $101.6(22.0) \ddagger$ & 98.0 (19.0)‡ \\
\hline Apo C-II (mg/dl) & $3.0(1.5)$ & $3.9(1.4) \ddagger$ & 3.8 (1.3)‡ & $4.1(1.4) \dagger$ \\
\hline Apo C-III (mg/dl) & $14.2(3.5)$ & $18.3(6.4) \ddagger$ & $17.7(4.8) \ddagger$ & $18.8(7.0) \ddagger$ \\
\hline Factor VIII activity (U/dl) & $101.8(23.9)$ & $115.8(34.5)^{*}$ & $121.2(39.0)$ & $102.3(23.9)$ \\
\hline BMI $\left(\mathrm{kg} / \mathrm{m}^{2}\right)$ & $23.4(5.4)$ & $25.9(6.1)$ & $26.0(9.3)$ & $25.9(4.9)$ \\
\hline
\end{tabular}

Values are mean (SD).

*Difference from patients without thrombosis $p \leqslant 0.05$.

†Difference from patients without thrombosis $p \leqslant 0.02$.

†Difference from patients without thrombosis $p \leqslant 0.01$.

$\S$ The analysis of venous and arterial thrombosis did not include the four patients with combined venous and arterial events.

Apo, apoliprotein; BMl, body mass index; HDL, high density lipoprotein; LDL, low density lipoprotein; Lp(a), lipoprotein (a); VLDL, very low density lipoprotein. 
Table 4 Lipid profile variables and factor VIII activity and their relative risk for thrombosis: comparison between Behçet's disease patients with and without thrombosis

\begin{tabular}{lll}
\hline Variable & OR $(95 \% \mathrm{CI})^{*} \dagger$ & $\mathrm{p}$ Value \\
\hline Total cholesterol & $1.3(0.97$ to 1.74$)$ & 0.08 \\
Triglyceride & $1.58(1.09$ to 2.30$)$ & 0.017 \\
LDL cholesterol & $1.12(0.8$ to 1.58$)$ & 0.5 \\
HDL cholesterol & $1.15(0.75$ to 1.75$)$ & 0.52 \\
VLDL cholesterol & $1.49(0.98$ to 2.26$)$ & 0.063 \\
Lp(a) & $0.83(0.57$ to 1.20$)$ & 0.32 \\
Apo A-I & $1.23(0.94$ to 1.6$)$ & 0.128 \\
Apo B-100 & $1.25(0.99$ to 1.58$)$ & 0.056 \\
Apo C-II & $1.59(1.13$ to 2.23$)$ & 0.008 \\
Apo C-III & $1.76(1.17$ to 2.65$)$ & 0.007 \\
Factor VIII activity & $1.39(1.002$ to 1.92$)$ & 0.049
\end{tabular}

${ }^{*}$ Odds ratio was calculated by logistic regression. Relative risk was calculated for any increase of $20 \mathrm{mg} / \mathrm{dl}(0.52 \mathrm{mmol} / \mathrm{l})$ in total cholesterol and LDL; and for any increase of $10 \mathrm{mg} / \mathrm{dl}(0.26 \mathrm{mmol} / \mathrm{l})$ in $\mathrm{HDL}, \mathrm{VLDL}$, Lp(a), apo $A$, and apo $B$; and for any increase of $40 \mathrm{mg} / \mathrm{dl}(0.45 \mathrm{mmol} /$ I) in the triglyceride level; and for any increase of $1 \mathrm{mg} / \mathrm{dl}$ in Apo C-II and of $4 \mathrm{mg} / \mathrm{dl}$ in Apo C-III. Odds ratio was also calculated for any increase of $20 \mathrm{U} / \mathrm{dl}$ in factor VIII levels.

†Odds ratio values were adjusted for confounding variables including $\mathrm{BMl}$, age, and sex.

Apo, apoliprotein; $\mathrm{BMI}$, body mass index; $\mathrm{Cl}$, confidence interval; $\mathrm{HDL}$, high density lipoprotein; LDL, low density lipoprotein; Lp(a), lipoprotein (a); OR, odds ratio; VLDL, very low density lipoprotein.

When apolipoproteins were also considered as potential risk factors, the strongest marker found to be associated with the occurrence of thrombosis was apolipoprotein C-III $(p=0.002)$. The estimated odds ratio for thrombosis associated with an increase of $4 \mathrm{mg} / \mathrm{dl}$ in apolipoprotein C-III concentration was 1.76 (95\% CI, 1.17 to 2.65$)$. There was, however, a highly positive correlation between apolipoprotein C-III and triglyceride concentration, so that once apolipoprotein C-III was accounted for, there was no additional predictive value associated with triglyceride concentration. These two variables were almost equally effective as markers associated with the occurrence of thrombosis.

\section{DISCUSSION}

The pathogenesis of arterial and venous thrombosis in Behçet's disease is not completely understood. It is generally accepted that vasculitis, a hallmark of Behçet's disease, partially explains the initiation of thrombosis in small as well as large blood vessels. ${ }^{13}$ Attempts to identify additional prothrombotic factors have so far been conflicting. For example, in Turkey, where the prevalence of Behçet's disease is probably the highest in the world, factor $\mathrm{V}$ Leiden was associated with the occurrence of thrombosis in several but not all studies, ${ }^{6}{ }^{14}$ and recent studies from Italy and Spain also did not reveal such an association. ${ }^{15}{ }^{16}$ In the present study none of the common prothrombotic polymorphisms nor homocysteine concentration was significantly associated with thrombosis. Increased factor VIII level, recently shown to be a risk factor for idiopathic venous thrombosis, ${ }^{17}$ was the only prothrombotic variable which appeared to be associated with the occurrence of thrombosis.

We are aware of the rather long lag period between the thrombotic events and the analyses performed, related to the retrospective nature of our study. However, such possible bias would have affected both the thrombotic and the nonthrombotic group.

The main finding in this study was the lack of significant association between any of the thrombophilic factors and thrombosis in Behçet's disease patients. Interestingly, an association between thrombosis and dyslipidaemia was found. Traditionally, dyslipidaemia has been associated with atherothrombotic diseases. In recent years, idiopathic venous thrombosis was thought to be associated with hypertriglyceridaemia; however, after adjustment for BMI, triglycerides were not found to be an independent risk factor for venous thrombosis. ${ }^{18}$ Nevertheless, hypercholesterolaemia, ${ }^{19}$ increased serum concentration of lipoprotein (a), ${ }^{20}$ and decreased plasma concentration of glucosylceramide ${ }^{7}$ are associated with a thrombotic tendency. The mechanisms whereby dyslipidaemic changes affect blood coagulability vary, as recently reviewed elsewhere. ${ }^{21}$ For example, triglyceriderich lipoproteins such as VLDL enhance the conversion of prothrombin to thrombin by factor $\mathrm{Xa}^{22}$ and augment the activation of factor VII by factor $\mathrm{Xa},{ }^{23}$ whereas glucosylceramide, a neutral glycosphingolipid, augments the inactivation of factor Va by activated protein C. ${ }^{7}$ Consequently, increased concentrations of VLDL and decreased concentrations of glucosylceramide augment thrombin generation, the former by increased procoagulant activity and the latter by decreased anticoagulant activity. Lipoprotein (a) apparently competes with plasminogen owing to structural homology and thus an increased concentration of this component may lead to decreased fibrinolysis. ${ }^{20}$

In the current study neither increased mean concentration of lipoprotein (a) nor decreased mean concentration of glucosylceramide was observed in Behçet's disease patients with thrombosis compared with patients without thrombosis. In contrast, the main statistically significant differences between these groups were in mean concentrations of total cholesterol, triglycerides, VLDL, and apolipoproteins B-100, C-II, and C-III (table 3). The multistep regression analysis showed that the concentration of either triglycerides or apo C-III were the best markers associated with the occurrence of thrombosis.

Why some patients with Behçet's disease manifest changes in their lipid profile and others do not remains to be established. It is also unclear at the present time whether the use of lipid lowering agents would decrease the morbidity associated with major thrombotic events affecting patients with Behçet's disease. However, such an option should be borne in mind in view of a recent study which suggested that the use of statins reduces the risk of idiopathic venous thrombosis. ${ }^{24}$

\section{Authors' affiliations}

M Leiba, Y Sidi, H Gur, M Ehrenfeld, Department of Internal Medicine C, Sheba Medical Centre,Tel-Hashomer, Israel

U Seligsohn, N Rosenberg, Thrombosis and Haemostasis Research

Institute, Sheba Medical Centre

D Harats, Institute of Lipid and Atherosclerosis Research, Sheba Medical Centre

B A Sela, Institute of Chemical Pathology, Sheba Medical Centre J H Griffin, Department of Molecular and Experimental Medicine, Scripps Research Institute, La Jolla, California, USA

A Livneh, Department of Internal Medicine F, Sheba Medical Centre I Gelernter, Statistics Laboratory, Tel-Aviv University, Ramat-Aviv, Israel

We thank Professor David Steinberg from the Statistics Laboratory, TelAviv University, for his advice in the statistical analyses, Dr Hiroshi Deguchi and Ms Young Mee Lee (The Scripps Research Institute) for measuring plasma glucosylceramide, and Dr Adi Leiba, Department of Internal Medicine D, Sheba Medical Centre, for invaluable assistance and support.

Grant support: Katznelbogen grant, Sackler Faculty of Medicine, TelAviv University; and National Institutes of Health grant HLZ1544.

\section{REFERENCES}

1 Sakane T, Takeno M, Suzuki N, Inaba G. Behcet's disease. N Engl J Med 1999;341:1284-91.

2 Gul A, Ozbek U, Ozturk C, Inanc M, Konice M, Ozcelik T. Coagulation factor $\checkmark$ gene mutation increases the risk of venous thrombosis in Behcet's disease. Br J Rheumatol 1996;35:1 178-80. 
3 Kuzu MA, Ozaslan C, Koksoy C, Gurler A, Tuzuner A. Vascular involvement in Behcet's disease: 8 year audit. World J Surg 1994;18:948-54.

4 Leiba M, Sidi Y, Gur H, Leiba A, Ehernfeld M. Behcet's disease and thrombophilia. Ann Rheum Dis 2001;60:1081-5.

5 Ozatli D, Sayinalp N, Buyukasik Y, Karakus S, Haznedaroglu IC, Kirazli S, et al. Unchanged global fibrinolytic capacity despite increased factor Vlla activity in Behcet's disease: evidence of a prethrombotic state. Rheumatol Int 2002;21:137-40.

6 Kiraz S, Ertenli I, Ozturk MA, Haznedaroglu IC, Celik I, Calguneri M Pathological haemostasis and "prothrombotic state" in Behcet's disease. Thromb Res 2002;105:125-33.

7 Deguchi H, Fernandez JA, Pabinger I, Heit JA, Griffin JH. Plasma glucosylceramide deficiency as potential risk factor for venous thrombosis and modulator of anticoagulant protein $C$ pathway. Blood 2001;97:1907-14.

8 Wechsler B, Davatchi F, Hamza M, Dilsen N, Kansu E, et al. Criteria for diagnosis of Behcet's disease - International Study Group for Behcet's disease. Lancet 1990;335: 1078-80

9 Salomon O, Steinberg DM, Zivelin A, Gitel S, Dardik R, Rosenberg N, et al. Single and combined prothrombotic factors in patients with idiopathic venous thromboembolism: prevalence and risk assessment. Arterioscler Thromb Vasc Biol 1999; 19:511-18.

10 Jacobsen DW, Gatautis VJ, Green R, Robinson K, Savon SR, Secic M, et al. Rapid HPLC determination of total homocysteine and other thiols in serum and plasma: sex differences and correlation with cobalamin and folate concentrations in healthy subjects. Clin Chem 1994;40:873-81.

11 Rifai N, Silverman LM. Immunoturbidimetric techniques for quantifying apolipoproteins CII and CIII. Clin Chem 1986;32:1969-72.

12 Noma A, Hata Y, Goto Y. Quantitation of serum apolipoprotein A-I, A-II, B, C-II, C-III and $E$ in healthy Japanese by turbidimetric immunoassay: reference values, and age- and sex-related differences. Clin Chim Acta $1991 ; 199: 147-57$.

13 Ehrlich GE. Vasculitis in Behcet's disease. Int Rev Immunol 1997;14:81-8.
14 Toydemir PB, Elhan AH, Tukun A, Toydemir R, Gurler A Tuzuner A, et al. Effects of factor $V$ gene $G 1691 A$, methylenetetrahydrofolate reductase gene C677T, and prothrombin gene G20210A mutations on deep venous thrombogenesis in Behcet's disease. J Rheumatol 2000;27:2849-54.

15 Siliagardi M, Ghirarduzzi A, lori I, Salvarani C, Boiardi L, Bellesia E, et al. Factor V Leiden and G20210A prothrombin alleles are not associated with thrombosis in Behcet's disease [abstract]. Thromb Haemost $2001 ; 85$ (suppl):2519.

16 Espinosa G, Font J, Tassies D, Vidaller A, Deulofeu R, Lopez-Soto A, et al. Vascular involvement in Behcet's disease: relation with thrombophilic factors, coagulation activation, and thrombomodulin. Am J Med 2002;1 12:37-43.

17 Koster T, Blann AD, Briet E, Vandenbroucke JP, Rosendaal FR. Role of clotting factor VIII in effect of von Willebrand factor on occurrence of deep-vein thrombosis. Lancet 1995;345:152-5.

18 Vaya A, Mira Y, Fernando F, Contreras M, Estelles A, Espana F, et al. Hyperlipidemia and venous thromboembolism in patients lacking thrombophilic risk factors. Br J Haematol 2002; 1 18:255-9.

19 Kawasaki T, Kambayashi J, Ariyoshi H, Sakon M, Suehisa E, Monden M. Hypercholesterolemia as a risk factor for deep-vein thrombosis. Thromb Res 1997;88:67-73.

20 von Depka M, Nowak-Gottl U, Eisert R, Dieterich C, Barthels M, Scharrer I, et al. Increased lipoprotein (a) levels as an independent risk factor for venous thromboembolism. Blood 2000;96:3364-8.

21 Griffin JH, Fernandez JA, Deguchi H. Plasma lipoproteins, hemostasis and thrombosis. Thromb Haemost $2001 ; 86: 386-94$.

22 Moyer MP, Tracy RP, Tracy PB, van't Veer C, Sparks CE, Mann KG. Plasma lipoproteins support prothrombinase and other procoagulant enzymatic complexes. Arterioscler Thromb Vasc Biol 1998;18:458-65.

23 Kjalke M, Silveira A, Hamsten A, Hedner U, Ezban M. Plasma lipoproteins enhance tissue factor-independent factor VII activation. Arterioscler Thromb Vasc Biol 2000;20:1835-41.

24 Ray JG, Mamdani M, Tsuyuki RT, Anderson DR, Yeo EL, Laupacis A. Use of statins and the subsequent development of deep vein thrombosis. Arch Intern Med 2001;161:1405-10. 